\title{
Palladium(II)-Catalyzed Annulation between ortho-Alkenylphenols and Allenes. Key Role of the Metal Geometry in Determining the Reaction Outcome
}

\author{
Noelia Casanova, Karina P. Del Rio, Rebeca García-Fandiño, José L. Mascareñas,* and Moisés Gulías* \\ Centro Singular de Investigación en Química Biolóxica e Materiais Moleculares (CIQUS) and Departamento de Química Orgánica, \\ Universidade de Santiago de Compostela, 15782 Santiago de Compostela, Spain
}

\section{Supporting Information}

\begin{abstract}
Alkenylphenols react with allenes, upon treatment with catalytic amounts of $\mathrm{Pd}(\mathrm{II})$ and $\mathrm{Cu}(\mathrm{II})$, to give benzoxepine products in high yields and with very good regio- and diastereoselectivities. This contrasts with the results

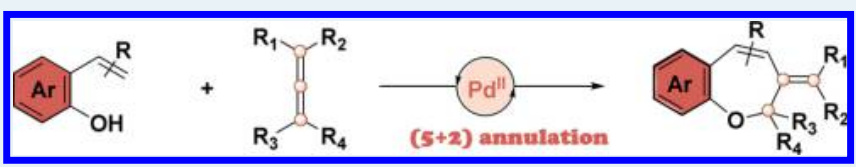
obtained with $\mathrm{Rh}$ catalysts, which provided chromene-like products through a pathway involving a $\beta$-hydrogen elimination step. Computational studies suggest that the square planar geometry of the palladium is critical to favor the reductive elimination process required for the formation of the oxepine products.
\end{abstract}

KEYWORDS: $\mathrm{C}-\mathrm{H}$ activation, oxepine, cycloaddition, palladium, allene

$\mathrm{H}$ eterocyclic compounds are prevalent in medicinal chemistry, and therefore, there is a continued interest in the development of practical methods for their assembly from simple precursors. ${ }^{1}$ In this context, the use of synthetic protocols involving transition-metal-catalyzed $\mathrm{C}-\mathrm{H}$ functionalizations is especially appealing. ${ }^{2}$ In recent years, there has been an increasing number of reports on the assembly of heterocycles through annulation reactions involving $\mathrm{C}-\mathrm{H}$ activation processes. While most of these reactions use alkynes, alkenes, or carbon monoxide as cycloaddition partners, ${ }^{3,4}$ allenes, which are highly attractive owing to their intrinsic reactivity and versatility, have been very scarcely employed. ${ }^{5}$

Recently we found that 2-alkenylphenols can react with allenes upon treatment with $\mathrm{Cp} * \mathrm{Rh}$ (III) catalysts to give chromene-type products (A, Scheme 1A). ${ }^{6}$ The reaction, which can be formally viewed as a $(5+1)$ annulation, was proposed to involve the activation of the terminal olefinic sp2 $\mathrm{C}-\mathrm{H}$ bond, followed by allene insertion to generate a $\pi$-allyl intermediate like B (Scheme 1B). This complex evolves to the product through $\beta$-hydrogen elimination followed by two consecutive pericyclic rearrangements of the resulting triene. We envisioned that moving from $\mathrm{Cp}^{*} \mathrm{Rh}$ to a $\mathrm{Pd}$ complex, and therefore from a pseudo-octahedral to a square planar geometry, might favor the reductive elimination processes in intermediates of type $C$ and hence the generation of appealing benzooxepine products.

Herein we demonstrate that indeed readily available 2alkenylphenols can react with a broad range of allenes in a formal $(5+2)$ cycloaddition when treated with $\mathrm{Pd}(\mathrm{II})$ catalysts under oxidative conditions (Scheme 1C). The reaction provides a wide variety of interesting benzoxepine products in high yields and with excellent regio- and diastereoselectivties $(E / Z)$.

We started our research by assaying the reaction between alkenylphenol 1a and phenylallene $2 \mathrm{a}$. The initial conditions
Scheme 1. Rh(III) vs Pd(II) Annulation of orthoAlkenylphenols with Allenes

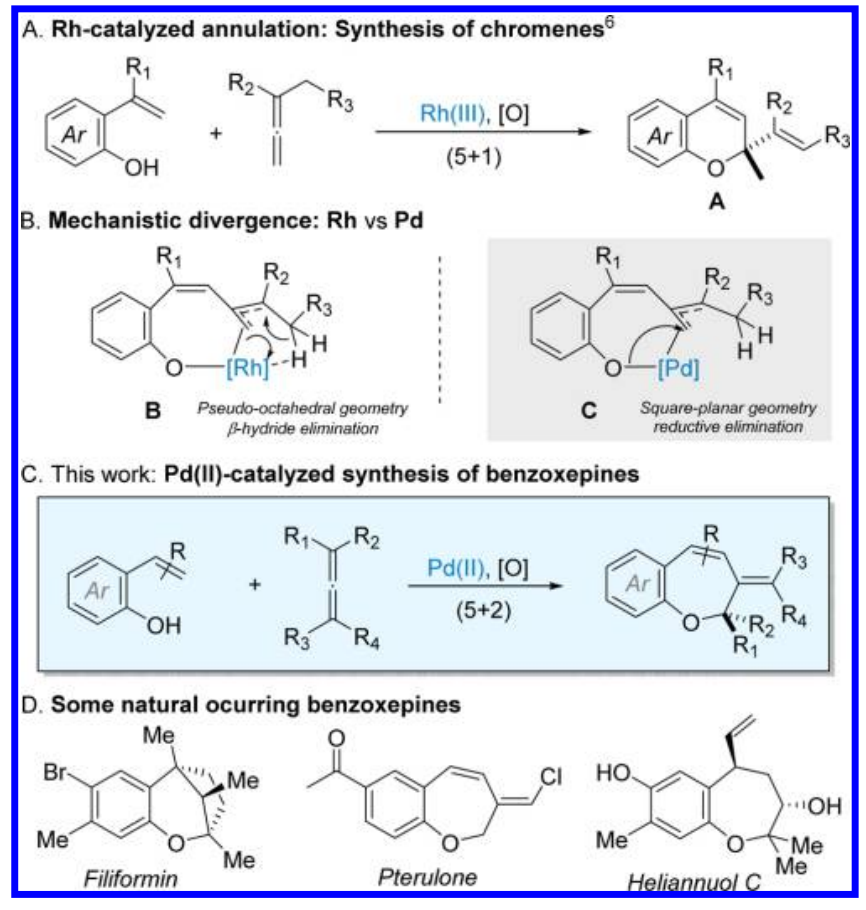

consisted of heating of a 1.5:1 mixture of both substrates with $\mathrm{Pd}(\mathrm{OAc})_{2}$ at $85^{\circ} \mathrm{C}$, in acetonitrile, in the presence of 0.5 equiv of $\mathrm{Cu}(\mathrm{OAc})_{2}$, and under air. After $6 \mathrm{~h}$, the crude ${ }^{1} \mathrm{H}$ NMR

Received: March 13, 2016

Revised: April 13, 2016

Published: April 14, 2016 
showed the formation of a mixture of three adducts that were identified as the desired oxepines 3aa (5.3:1 ratio of $E / Z$ isomers) and the regioisomeric oxepine 4aa, in a 1.8:1 ratio. ${ }^{7}$ Albeit the regioselectivity was low, the reaction took place with a good overall yield of $76 \%$ (Table 1). While using tert-amyl

Table 1. Optimization of the Reaction ${ }^{a, b}$

\begin{tabular}{|c|c|c|c|c|c|c|}
\hline $1 a$ & $\begin{array}{l}\mathrm{Ph} \\
\mathrm{Pd}(\mathrm{OAC} \\
\mathrm{Cu}(\mathrm{O} \\
(0.5 \\
\text { solve }\end{array}$ & $\begin{array}{l}\text { Me } \\
2(7.5 \mathrm{~mol} \\
\text { c) })_{2} \cdot \mathrm{H}_{2} \mathrm{O} \\
\text { quiv), air } \\
\text { t, ligand }\end{array}$ & $\nabla$ & aa & $4 a$ & \\
\hline entry & solvent & $T\left({ }^{\circ} \mathrm{C}\right)$ & ligand & $3 a a / 4 a a$ & $E: Z$ (3аa) & yield \\
\hline 1 & $\mathrm{CH}_{3} \mathrm{CN}$ & 85 & - & $1.8: 1$ & $5.3: 1$ & $76 \%$ \\
\hline 2 & $t$-AmylOH & 100 & - & $2.6: 1$ & $>20: 1$ & $48 \%$ \\
\hline 3 & toluene & 110 & - & $3.9: 1$ & $>20: 1$ & $66 \%$ \\
\hline 4 & toluene & 110 & pyridine & $3: 1$ & $>20: 1$ & $\sim 20 \%$ \\
\hline 5 & toluene & 110 & $2-\mathrm{PhPy}^{c}$ & $3.7: 1$ & $\sim 10: 1$ & $54 \%$ \\
\hline 6 & toluene & 110 & $\mathrm{DAFO}^{d}$ & $3.4: 1$ & $\sim 18: 1$ & $71 \%$ \\
\hline 7 & toluene & 110 & $2,2^{\prime}$-Bipy & $9: 1$ & $>20: 1$ & $84 \%$ \\
\hline 8 & toluene & 110 & 2,2'-Bipy & $9: 1$ & $>20: 1$ & $56 \%^{e}$ \\
\hline
\end{tabular}

${ }^{a}$ Reaction conditions: $0.25 \mathrm{mmol}$ of $2 \mathrm{a}, 0.37 \mathrm{mmol}$ of $1 \mathrm{a}, 2 \mathrm{~mL}$ of solvent. ${ }^{b}$ Isolated yields based on $2 \mathrm{a}$ after $15 \mathrm{~h} .{ }^{c}$ 2-Phenylpyridine. $d_{4,5}$-Diazafluoren-9-one (DAFO). ${ }^{e} 20 \mathrm{~mol} \%$ of $\mathrm{Cu}(\mathrm{OAc})_{2} \cdot \mathrm{H}_{2} \mathrm{O}$.

alcohol as solvent led to lower conversions (entry 2), changing to toluene improved the isomeric ratios (entry 3 ). We then tested the effect of some additives with coordinating ability like pyridine or 2-phenylpyridine, or bidentate derivatives like 4,5diazafluoren-9-one, but the efficiency of the reaction was lower (entries 4-6). However, in the presence of $7.5 \% 2,2^{\prime}$-bipyridine $\left(2,2^{\prime}\right.$-Bipy) the reaction led to a good yield of the 2,3dihydrobenzo[ $b]$ oxepines ( $84 \%$ yield), which were produced with very good regio- and diastereoselective ratios (entry 7).

We then investigated the scope of the reaction with regard to the allene component (Scheme 2). In most of the cases, the standard conditions of entry 1 (Table 1 ) gave very good yields of the adducts without the need of additives (conditions A), but in some cases, the conditions with Bipy were beneficial (conditions B).

Therefore, the symmetrical 1,3-disubstituted allenes 1,3diphenylpropa-1,2-diene (2b) and 4,5-nonadiene (2c) provided the corresponding products $3 \mathbf{a b}$ and $3 \mathrm{ac}$ with good yield and excellent $E: Z$ ratios. Similarly the cyclic allene cyclonona-1,2diene led to the expected product $3 \mathrm{ad}$ as only product. 1,1Disubsubstituted allenes are also efficient cycloaddition partners (3ae-3ag obtained in $71-92 \%$ yield) with excellent regioselectivities. Monosubstituted allenes like phenylallene or cyclohexylallene also participated in the process, leading to the products 3ah and 3ai in 69 and $71 \%$ yields, respectively. In these cases, we found that using 2,2'-bipyridine as additive is important in order to achieve good selectivities. Finally, we tested two trisubstituted allenes that led to the products 4aj and 4ak in excellent yields and selectivities. These allenes favored the formation of regioisomers featuring challenging tetrasubstituted carbons in the cyclic framework, probably because of the preferred formation of phenyl-conjugated products.

As shown in the Scheme 3, the reaction is not restricted to 2alkenylphenols like 1a but also works with related substrates bearing other substituents at the internal position of the alkene, such as ethyl or phenyl, and is also efficient with 2hydroxystyrene; however, in this case, a small amount of the
Scheme 2. Scope with Different Allenes ${ }^{a, b}$

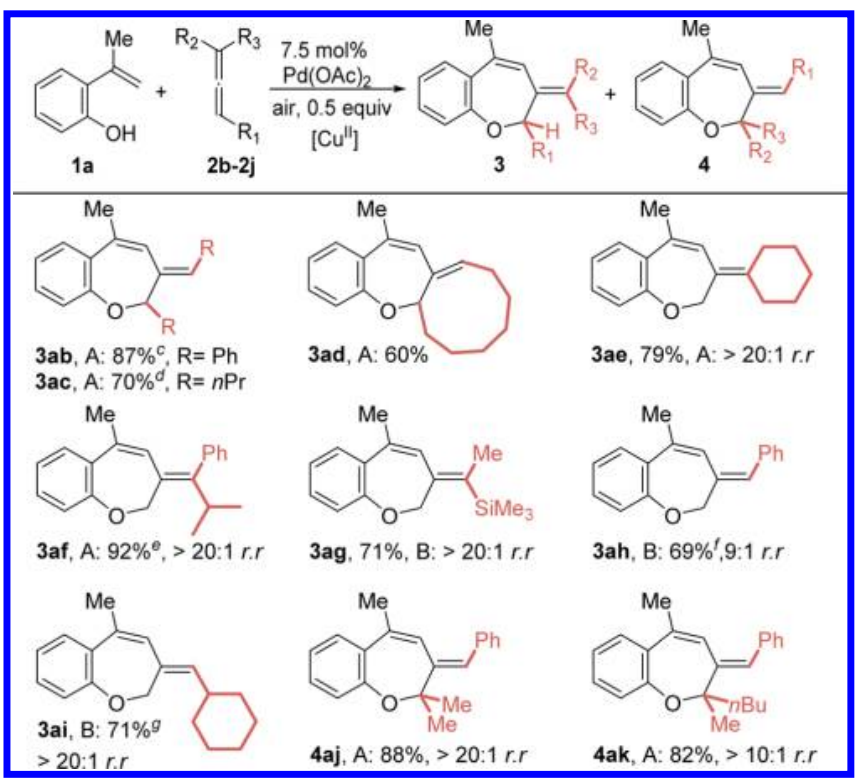

${ }^{a}$ Conditions A: $\mathrm{CH}_{3} \mathrm{CN}, 85^{\circ} \mathrm{C}$; conditions B: $7.5 \mathrm{~mol} \%$ of 2,2'-Bipy, toluene $110{ }^{\circ} \mathrm{C}$. See SI. ${ }^{b}$ Structure of the major product shown. Isolated yields based on 2. $E / Z$ ratios and regioisomeric ratios (r.r.) determined by ${ }^{1} \mathrm{H}$ NMR spectroscopy of crude mixtures. ${ }^{c} E: Z=10: 1$. ${ }^{d} E: Z=16: 1 .{ }^{e} E: Z=2.7: 1 .{ }^{f} E: Z=3.2: 1 .{ }^{g} E: Z=1.8: 1$.

Scheme 3. Scope with respect to the Alkenylphenol Component ${ }^{a, b}$

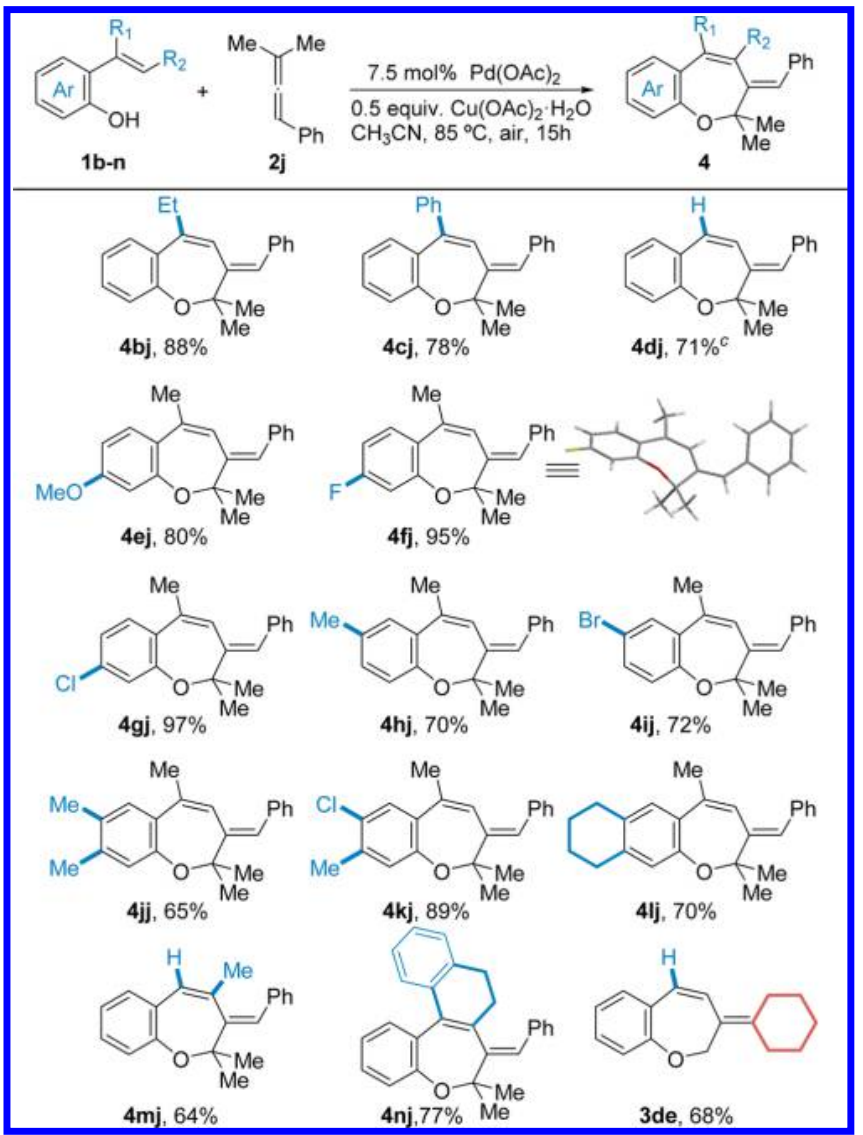

${ }^{a}$ Isolated yield based on allenes $2 .{ }^{b} E: Z$ and regioisomeric ratios are $>20: 1$, unless otherwise noted. ${ }^{c}$ r.r. $=12: 1$. 
other regioisomer is formed. In all the cases the expected oxepine adducts were obtained in excellent yields (4bj-4dj, $71-$ $88 \%$ yields). We also analyzed the reactivity of precursors with different substituents in the phenyl moiety of the alkenylphenol.

Substituents in para position to the alkenyl group are welltolerated irrespective of whether they are electron donors (4ej, $80 \%$ yield) or electron withdrawing $\left(\mathbf{4 f j}{ }^{8}\right.$ and $\mathbf{4 g j}$, $95 \%$ and $97 \%$ yield, respectively). Similarly, aromatic substrates with substituents para to the hydroxyl group work very well (4hj and 4ij, 70-72\% yield), as occurs with disubstituted derivatives $\mathbf{1 j}$, $1 \mathbf{k}$, and $\mathbf{1 1}$ (65-89\% yield of products). Interestingly, substrates with substituents at the terminal position of the alkene such as $1 \mathbf{m}$ and $\mathbf{1 n}$ also worked, producing the corresponding products in $64 \%$ and $77 \%$ yield as single isomers. This is noteworthy because previous Rh-catalyzed annulation processes failed with this type of alkenes. ${ }^{6,3 c, d}$ Finally, and as expected, allenes other than $2 \mathbf{j}$ can be used with different alkenylphenols (see for instance $3 \mathrm{de}$ ).

Overall, the transformation represents a versatile, atom economical entry to a great variety of benzoxepine skeletons equipped with functionalities susceptible of further elaboration. Thus, for instance, the crude adduct resulting from the annulation between $\mathbf{1 d}$ and the allene $2 \mathbf{j}$ can be easily hydrogenated to the corresponding saturated product $\mathbf{5}$ with excellent yield.

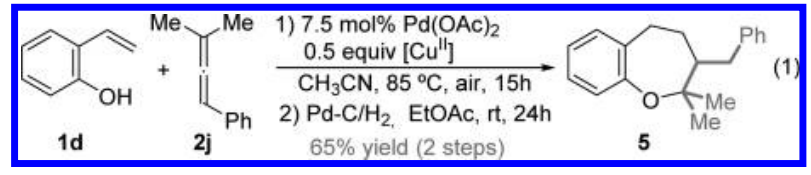

Studies with deuterated substrates provided valuable mechanistic insights. A competition experiment using 1d and its dideuterated derivative (1d- $d_{2}, 98 \%$ deuterated) allowed us to calculate a kinetic isotopic effect (KIE) of 2.3 (Scheme 4, eq 1 ), which suggest the $\mathrm{C}-\mathrm{H}$ bond cleavage has influence in the reaction rate. Interestingly, treatment of (Z)-1d- $d$ (90\% deuterated) with palladium acetate under standard conditions leads to a total stereochemical scrambling of the deuterium in

\section{Scheme 4. Mechanistic Experiments}

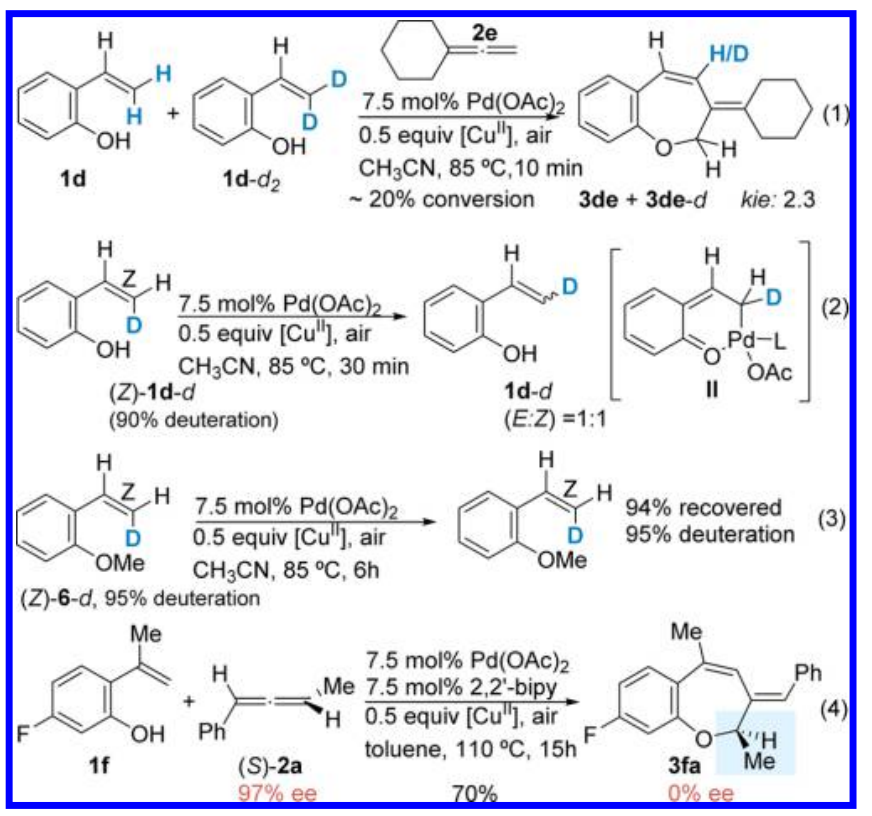

less than $30 \mathrm{~min}$ (eq 2). However, this isomerization does not occur in the case of the methoxy derivative (Z)-6-d, even after 6 $\mathrm{h}$ (eq 3). ${ }^{9}$ These data are consistent with the rapid formation of species like II, which can easily reverse to the starting material. It was also informative to observe that reaction with the optically active allene $(S)$-2a leads to a racemic product, which strongly suggests the formation of an achiral $\pi$-allyl intermediate (eq 4).

A plausible catalytic cycle consistent with the above data would involve an initial ligand exchange between the phenol derivative $\mathbf{1}$ and the palladium acetate complex to give a species of type I, which can evolve by intramolecular attack of the conjugated alkene to the palladium center to give an intermediate like II (or $\left.\mathbf{I I}^{\prime}\right)$. This intermediate could then undergo a base-induced rearomatization to form a sixmembered palladacycle III (see Scheme 5). Albeit the current data fit with this hypothesis, a $\mathrm{C}-\mathrm{H}$ activation involving a concerted metalation-deprotonation cannot be fully discarded.

\section{Scheme 5. Plausible Reaction Mechanism}

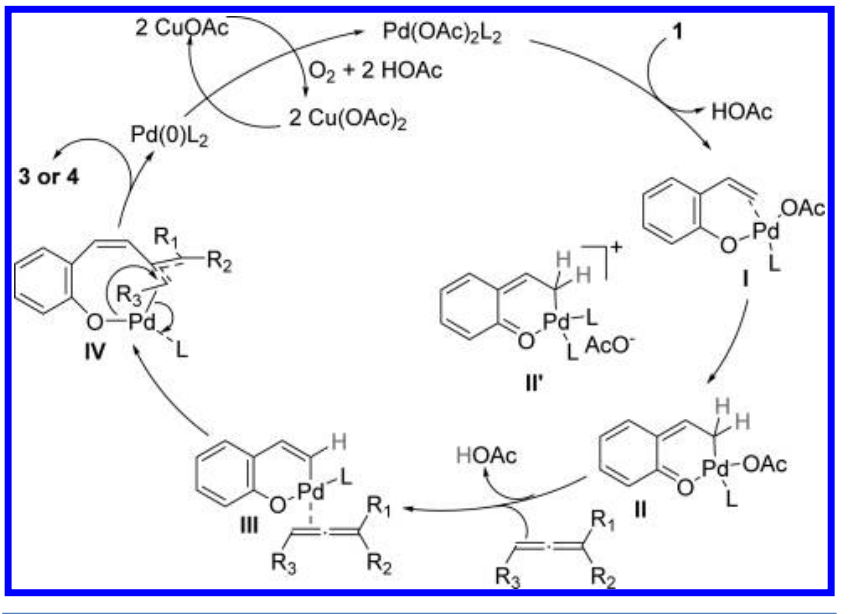

Next step consists of coordination of the allene followed by a regioselective migratory insertion to give a $\pi$-allylic palladacycle $\mathbf{I V}{ }^{10}$ which undergoes a reductive elimination step to the benzoxepine products. The resulting $\operatorname{Pd}(0)$ species is reoxidized to $\mathrm{Pd}(\mathrm{II})$ by copper diacetate and air. The selectivity of the ring closing depends on the allene structure and electronic characteristics of the substituents.

Although the above scheme presents a feasible mechanistic scenario, the reasons behind the different outcomes of the palladium and rhodium catalyzed processes are intriguing. Therefore, we carried out density functional calculations to compare the energetic profiles. ${ }^{11}$ As allenic substrate, we used vinylidenecyclohexane (2e), which showed divergent reactivity with $\left[\mathrm{Cp}^{*} \mathrm{RhCl}_{2}\right]_{2} / \mathrm{Cu}(\mathrm{OAc})_{2},{ }^{6}$ or $\mathrm{Pd}(\mathrm{OAc})_{2} / \mathrm{Cu}(\mathrm{OAc})_{2}$ (Scheme 3 ). In consonance with the experimental results, the activation barrier for the reductive elimination from $\mathbf{I V}^{\mathbf{P d}}$ is lower than that required for the $\beta$-hydrogen elimination (Figure 1 , paths black and gray). More importantly, the energy cost for the reductive elimination is much lower than that from a similar intermediate with the $\mathrm{Cp} * \mathrm{Rh}$ complex $\left(\mathrm{IV}^{\mathrm{Rh}}\right.$, black vs blue path). ${ }^{11}$

The different energetic barriers for the reductive elimination using rhodium and palladium catalysts can be readily explained by comparing the structures of the $\pi$-allyl metal complexes IV and the corresponding TSs. The $\pi$-allyl-palladium complex $\mathbf{I V}^{\mathbf{P d}}$ and $\mathbf{T S}_{\mathbf{1}}$ present a very similar geometry, as can be readily 


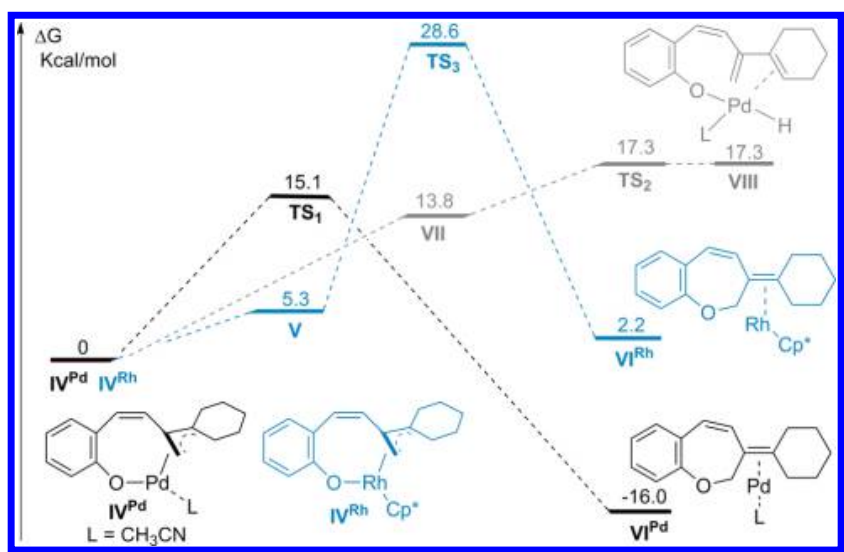

Figure 1. Energetic profiles of two pathways for Pd, and the reductive elimination for Rh. For details, see the Supporting Information. ${ }^{11,12}$

appreciated by comparing dihedral angles of the atoms shown in green in Figure 2. However, in the case of rhodium, the

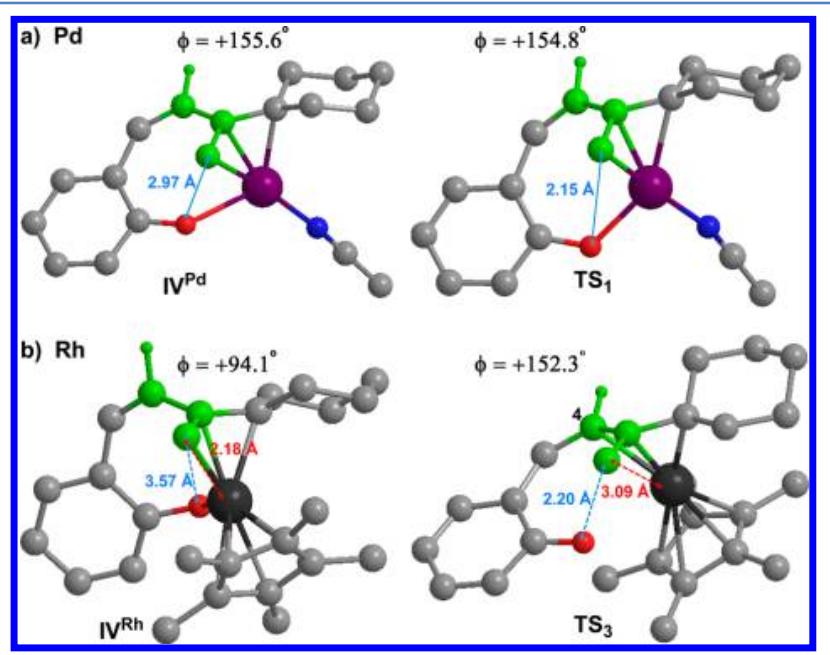

Figure 2. $\pi$-Allyl metal complexes and TSs for the reductive elimination. Most hydrogens removed for clarity.

conformation of the starting $\pi$-allyl complex is substantially different from that of $\mathbf{T S}_{3}$. Therefore, going from $\mathbf{I V}^{\mathrm{Rh}}$ to $\mathbf{T S}_{3}$ requires an important distortion (dihedral angle HCCC +94 in $\mathbf{I V}^{\mathrm{Rh}}$, and +152 in $\mathbf{T S}_{3}$, atoms in green, see Figure 2), which is energetically costly. Moreover, and in contrast to what happens with $\mathrm{Pd}$, in $\mathrm{TS}_{3}$ the rhodium loses part of the $\pi$-allylic coordination, which might further contribute to destabilize the system, although there is certain coordination to C4. Thus, the highest activation barrier for the reductive elimination with the $\mathrm{Cp} * \mathrm{Rh}$ complex seems to be associated with the geometrical constrains of its pseudo-octahedral geometry. In contrast, the square planar geometry of the palladium fits very well with the structure required for the reductive elimination process. ${ }^{13}$ This dichotomy associated with the metal geometry might also explain other divergent outcomes of reactions promoted by $\mathrm{Rh}(\mathrm{III})$ or $\mathrm{Pd}(\mathrm{II})$. $^{5}$

In summary, we have developed a straightforward and selective access to a wide range of benzoxepine skeletons through a palladium-catalyzed $(5+2)$ formal cycloaddition involving a $\mathrm{C}-\mathrm{H}$ activation process. This is one of the scarce examples of annulations based on the cleavage of $\gamma-\mathrm{C}-\mathrm{H}$ bonds which involve the use of allenes, as well as one of the very few leading to seven-membered rings. Remarkably, the method has a much higher scope with respect to both, the alkenyl phenol component and the allene, than the rhodiumcatalyzed annulations, ${ }^{6}$ and even allows the formation of cycles with tetrasubstituted carbons. Computational studies support the hypothesis that the different course of the reaction promoted by $\mathrm{Pd}(\mathrm{II})$ or by $\mathrm{Cp} * \mathrm{Rh}(\mathrm{III})$ catalysts can be ascribed to the geometric requirements associated with their respective square planar or a pseudo-octahedral geometries.

\section{ASSOCIATED CONTENT}

\section{Supporting Information}

The Supporting Information is available free of charge on the ACS Publications website at DOI: 10.1021/acscatal.6b00739.

Detailed experimental procedures, characterization data, computational details, and other information (PDF) $\mathrm{X}$-ray crystallographic analysis, compound $\mathbf{4 f j}$ (CIF) $\mathrm{X}$-ray crystallographic analysis, compound 3ah (CIF) $\mathrm{X}$-ray crystallographic analysis, compound 4aj (CIF)

\section{AUTHOR INFORMATION}

\section{Corresponding Authors}

*E-mail: moises.gulias@usc.es.

*E-mail: joseluis.mascarenas@usc.es.

\section{Notes}

The authors declare no competing financial interest.

\section{ACKNOWLEDGMENTS}

This work was supported by the Spanish MINECO (grant: SAF2013-41943-R), the ERDF, the European Research Council (Advanced Grant No. 340055) and the Xunta de Galicia (grants: GRC2013-041 and 2015-CP082). We also thank the orfeo-cinqa CTQ2014-51912-REDC. K.P.D.R. thanks the Coordenação de Aperfeiçoamento de Pessoal de Nível Superior (CAPES, Brazil) for the Ph.D scholarship. We thank Dr. M. Martínez for XRD analysis. All calculations were carried out at Centro de Supercomputación de Galicia (CESGA).

\section{REFERENCES}

(1) Eicher, T.; Hauptmann, S.; Suschitzky, H. The Chemistry of Heterocycles: Structures, Sunthesis, Reactions and Applications; WileyVCH: Weinhein, 2003.

(2) For selected recent reviews of metal-catalyzed $\mathrm{C}-\mathrm{H}$ functionalizations, see: (a) Wencel-Delord, J.; Glorius, F. Nat. Chem. 2013, 5, 369-375. (b) Engle, K. M.; Mei, T.-S.; Wasa, M.; Yu, J.-Q. Acc. Chem. Res. 2012, 45, 788-802. (c) Yeung, C. S.; Dong, V. M. Chem. Rev. 2011, 111, 1215-1292. (d) Ackermann, L. Acc. Chem. Res. 2014, 47, 281-295. (e) Fagnou, K. Top. Curr. Chem. 2009, 292, 35-56. (f) Lyons, T. W.; Sanford, M. S. Chem. Rev. 2010, 110, 1147-1169.

(3) For selected articles on Rh-catalyzed annulations involving $\mathrm{C}-\mathrm{H}$ activations, see: (a) Romanov-Michailidis, F.; Sedillo, K. F.; Neely, J. M.; Rovis, T. I. Am. Chem. Soc. 2015, 137, 8892-8895. (b) Dateer, R. B.; Chang, S. I. Am. Chem. Soc. 2015, 137, 4908-4911. (c) Seoane, A.; Casanova, N.; Quiñones, N.; Mascareñas, J. L.; Gulías, M. I. Am. Chem.

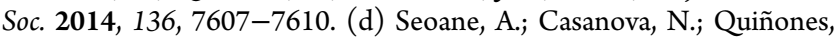
N.; Mascareñas, J. L.; Gulías, M. I. Am. Chem. Soc. 2014, 136, 834837. (e) Quiñones, N.; Seoane, A.; García-Fandiño, R.; Mascareñas, J. L.; Gulías, M. Chem. Sci. 2013, 4, 2874-2879. For a recent review, see: (f) Gulías, M.; Mascareñas, J. L. Angew. Chem., Int. Ed. 2016, 55, DOI: $10.1002 /$ anie.201511567R1.

(4) For selected articles on Pd-catalyzed annulations involving $\mathrm{C}-\mathrm{H}$ activations, see: (a) Kuram, M. R.; Bhanuchandra, M.; Sahoo, A. K. Angew. Chem. Int. Ed. 2013, 52, 4607-4612. (b) Dooley, J. D.; 
Chidipudi, S. R.; Lam, H. W. I. Am. Chem. Soc. 2013, 135, 1082910836. (c) Sasano, K.; Takaya, J.; Iwasawa, N. I.Am. Chem. Soc. 2013, 135, 10954-10957. (d) Sharma, U.; Kancherla, R; Naveen, T.; Agasti, S.; Maiti, D. Angew. Chem., Int. Ed. 2014, 53, 11895-11899. (e) Luo, S.; Luo, F.-X.; Zhang, X.-S.; Shi, Z.-I. Angew. Chem. Int. Ed. 2013, 52, 10598-10601. (f) McNally, A.; Haffemayer, B.; Collins, B. S. L.; Gaunt, M. I. Nature 2014, 510, 129-133. (g) Zuo, Z.; Liu, J.; Nan, J.; Fan, L.; Sun, W.; Wang, Y.; Luan, X. Angew. Chem. Int. Ed. 2015, 54, 15385-15389.

(5) For Pd-catalyzed annulations involving $\mathrm{C}-\mathrm{H}$ activations and allenes as reaction partners, see: (a) Suresh, R. R.; Swamy, K. C. K. I. Org. Chem. 2012, 77, 6959-6969. (b) Xia, X.-F.; Wang, Y.-Q.; Zhang, L.-L.; Song, X.-R.; Liu, X.-Y.; Liang, Y.-M. Chem. - Eur. J. 2014, 20, 5087-5091. (c) Rodríguez, A.; Albert, J.; Ariza, X.; Garcia, J.; Granell, J.; Farràs, J.; La Mela, A.; Nicolás, E. I. Org. Chem. 2014, 79, 95789585. For related rhodium oxidative $\mathrm{C}-\mathrm{H}$ bond activation/coupling process with allenes, see: (d) Kuppusamy, R.; Gandeepan, P.; Cheng, C.-H. Org. Lett. 2015, 17, 3846-3849. (e) Gandeepan, P.; Rajamalli, P.; Cheng, C.-H. Chem. - Eur. J. 2015, 21, 9198-9203. (f) Wang, H.; Glorius, F. Angew. Chem. Int. Ed. 2012, 51, 7318-7322. (g) Zeng, R; Fu, C.; Ma, S. I. Am. Chem. Soc. 2012, 134, 9597-9600. (h) Zeng, R.; Ye, J.; Fu, C.; Ma, S. Adv. Synth. Catal. 2013, 355, 1963-1970. (i) Wu, S.; Zeng, R.; Fu, C.; Yu, Y.; Zhang, X.; Ma, S. Chem. Sci. 2015, 6, 2275. For a related transformation catalyzed by $\mathrm{Ru}(\mathrm{II})$ see: (j) Nakanowatari, S.; Ackermann, L. Chem. - Eur. I. 2015, 21, 16246-16251.

(6) Casanova, N.; Seoane, A.; Mascareñas, J. L.; Gulías, M. Angew. Chem. Int. Ed. 2015, 54, 2374-2377.

(7) We did not observe spirocyclic products, which are formed in related reactions with alkynes. See, for instance: (a) Nan, J.; Zuo, Z.; Luo, L.; Bai, L.; Zheng, H.; Yuan, Y.; Liu, J.; Luan, X.; Wang, Y. I.Am. Chem. Soc. 2013, 135, 17306-17309. (b) Zuo, Z.; Yang, X.; Liu, J.; Nan, J.; Bai, L.; Wang, Y.; Luan, X. I. Org. Chem. 2015, 80, 3349-3356. (c) See also ref $3 c$.

(8) CCDC 1446125 (4fj) contains the supplementary crystallographic data for this paper. These data can be obtained free of charge from The Cambridge Crystallographic Data Centre via www.ccdc.cam. ac.uk/data_request/cif.

(9) For detailed mechanistic studies on the $E / Z$ isomerization of alkenes, see: Tan, E. H. P.; Lloyd-Jones, G. C.; Harvey, J. N.; Lennox, A. J. J.; Mills, B. M. Angew. Chem., Int. Ed. 2011, 50, 9602-9606.

(10) For addition to allenes with different regioselectivity, see: Zeng, R.; Wu, S.; Fu, C.; Ma, S. I. Am. Chem. Soc. 2013, 135, 18284-18287.

(11) For full details, see the SI.

(12) Intermediate $\mathbf{V}$ is a local minimum in which there is a coordination of the internal double bond to the rhodium.

(13) A reactivity switch promoted by different directing groups instead of metal complexes has been recently described: Kim, J.; Park, S.-W.; Baik, M.-H.; Chang, S. I. Am. Chem. Soc. 2015, 137, 1344813451 . 